\title{
Influencer Takip Etme ve Bırakma Kararına Yönelik Kullanıcı Deneyimleri
}

\author{
Seher Büşra Tokay (Yüksek Lisans Öğrencisi) \\ Erzincan Binali Yııdırım Üniversitesi Sosyal Bilimler Enstitüsü \\ busra.tokay@hotmail.com \\ Mustafa Şeref Akın (Prof. Dr.) \\ iD Erzincan Binali Yıldırım Üniversitesi İktisadi ve İdari Bilimler Fakültesi \\ mustafa.akin@erzincan.edu.tr
}

Başvuru Tarihi: 23.02.2021

Yayına Kabul Tarihi: 25.06.2021

Yayınlanma Tarihi: 30.07.2021

https://doi.org/10.17680/erciyesiletisim.885499

\section{Öz}

$\mathrm{Bu}$ makalede takipçilerin influencer takip etme veya bırakma kararlarının sebepleri araştırılmaktadır. Araştırma yöntemi etnografidir. Influencer takibine yönelik sosyal medya kullanıcılarının takipte oldukları ya da takibi bıraktıkları Influencerlarla ilgili mülakat yöntemiyle 16 kişi ile görüşmeler yapılmıștır. Analizde 3 ana başlık altında (gelişim, amaç ve gerçeklik) ikişer tane durum ortaya çıkmaktadır. Takipçisinin kişisel gelişimi desteklediğinde motive edici ve aydınlatıcıdır. Influencer, takipçisini gelişmekten yoksun bıraktığında yüzeysel ve hegemonyacıdır. Amacı faydalı ürün tanıtımında yönlendirici ve seçicidir. Ticari amacı ön plana çıktığında aldatıcı ve marka odaklıdır. Gerçeklikte, şeffaf olarak samimi ve kendisiyle barışıktır. Sahte hayat kurguladı̆̆ında manikür hayat ve şişirilmiş ego öne çıkmaktadır. Influencer başarıyı kendinde değil takipçileriyle kesişim noktalarında aramalıdır. Ünü yakaladıktan sonra samimiyetin yerine kendini ön planda tutması başarısını gölgelemektedir. Influencer kullanıcıların içinden olduğunu hissettirdiği zaman hem takipçi kitlesi çoğalmakta, hem de kullanıcıların gönüllerini kazanmaktadır. Kullanıcılar yapay sempatiden rahatsız olduğu için samimi gelmeyen influencerları takipten çıkarmaktadır. Influencerların paylaşımları toplumsal bilinci yükseltme yolunu izlediğinde kullanıcılar tarafından keyifle takip edilmektedir.

Anahtar Kelimeler: İletişim, Influencer, Motive Edici, Hegemonyacı. 


\title{
User Experiences Regarding the Decision to Follow and Leave Influencer
}

\author{
Seher Büşra Tokay (MA Student) \\ iD Erzincan Binali Yıldırım University Institute of Social Sciences \\ busra.tokay@hotmail.com \\ Mustafa Şeref Akın (Prof. Dr.) \\ D Erzincan Binali Yıldırım University Faculty of Economics and Administrative \\ mustafa.akin@erzincan.edu.tr
}

Date Received: 23.02.2021

Date Accepted: 25.06.2021

Date Published: 30.07.2021

https://doi.org/10.17680/erciyesiletisim.885499

\begin{abstract}
This article explores the reasons why followers decide to follow or quit influencers. The research method is ethnography. Interviews were held on the influencer that 16 social media users followed and left. In the analysis, two situations emerge under three main headings (development, purpose, and reality). It is motivating and enlightening when influencers support the personal development of followers. It is superficial and hegemonic when they deprive its follower of development. It is directive and selective in the promotion of useful products. When their commercial purposes come to the fore, they are deceptive and brand-oriented. They are sincere and at peace with themselves in personal transparency. Manicure life and inflated ego come to the picture when they set up fake life. The influencers should look for success at intersections with their followers. Keeping themselves in the foreground instead of sincerity after achieving fame overshadows their success. When the influencer makes the users feel like they are among them, the audience increases and gains the users' hearts.
\end{abstract}

Keywords: Communication, Influencer, Motivating, Hegemonist. 


\section{Giriş}

Türkiye'de akıllı cep telefonu kullanıcıları günün 7 saat 29 dakikasını sosyal medya platformlarında geçirmekteler. Sosyal medya platformlarına katılım açısından Türkiye Avrupa'da Facebook ve Instagram kullanımında ilk sıralardadır. 37 milyon aktif kullanıcı sayısı ile Facebook'ta dünyada onuncu sırada, 38 milyon kullanıcı sayısı ile Instagram'da dünyada altıncı sırada yer alır (Ünal, 2020). Bu mecralara olan ilginin artması sonucu reklam verenler ve markalar sosyal medyanın geniş kullanıcı kitlesine hitap edebilecek dijital dünyanın yeni ünlülerinden olan influencerlardan faydalanarak ürün pazarlamasında bulunmaktalar (Aslan \& Ünlü, 2016, s. 41).

Influencerın takipçileriyle ilişkilerini geliştirmeleri, takipçi sayılarını arttırmaları pazarlama açısından çok önemli hale gelmektedir. Ancak takipçiler influencerların kurguladıkları sahte hayatlarıyla ve ben-merkezci yaklaşımlarıyla kendilerine ticari olarak yaklaştıklarını gördüklerinde uzaklaşmaktalar (Tokay \& Akın, 2020). Bu makalede gerek ticari gerekse iletişim düzeyde şeffaflık ve sahte hayatın takipçiler üzerindeki etkileri incelenmektedir.

Influencerlar iki hedefe birden ulaşmaya çalışmaktalar: Kullanıcılarda oluşturduğu etkiyi ve takipçi sayısını arttırmak. Bu bağlamda incelenen çalışmada takipçilerin influencerların, takibi bırakılan ve takibe devam edilen kullanıcı duygularını derinlemesine araștırmaktadır. Bunun sonucunda iletişimde sessiz tarafı oluşturan takipçilerin beklentilerini, bırakma ve takip davranışlarını öğrenme fırsatı doğmaktadır. Makalede, influencerların takipçilerine hissettirdikleri olumlu ve olumsuz duygular değerlendirilmektedir.

\section{Literatür}

\subsection{Sosyal Medya ve Influencer}

Usenet Jim Ellis ve Tom Truscott' in 1979 yllında oluşturduğu ilk sosyal medya kuruluşudur. Bu kuruluş tüm dünya genelinde bulunan bireylere mesaj iletme avantajı sağlayan bir tartışma sahası oluşturmuştur. Open Diary Web sitesi Bruce ve Susan Abelson tarafından 1989 yılında oluşturulmuş ve sosyal medyanın gündelik kullanımı amacıyla çevrimiçi günlük yazarlarını bir araya toplamıştır. "Weblog" söylemi de aynı sürede meydana gelmiştir. 1990 yılında "Weblog" "we blog” (Blogluyoruz) biçiminde ifade edilmesi ile dijital iletişim geniş kitlere ulaşmıştır. İnternetin hızlanması ve geniş bant sistemlerinin kurulması sayesinde gelişmiş sosyal ağ sitelerinin (Facebook, MySpace) oluşmasıyla sosyal medya platformlarının gelişim aşamaları gerçekleşmiştir (İşlek, 2012, s. 17). Bu mecralarda yaşanan gelişmeler teknolojinin ilerlemesiyle birlikte yeni iş sahalarına kapı aralamıştır. Influencer, fenomen ve blogerlar bu yeni oluşumun getirdiği iș sahasında aktif rol oynamaktadır.

Cep telefonları, tabletler ve bilgisayarlar gibi cihazların kullanımının artmasıyla beraber tüm dünya ülkelerinde insanların sosyal medya kullanımı çoğalmaktadır. İnternet başında geçen zamanın çoğalmasıyla sosyal medya sitelerine ziyaret aynı hızda artmıştır (Bayuk \& Aslan, 2018, s. 183). İnsanların teknolojiyi takip etmesi sonucunda bireylerin sosyal medyanın etkileyici dünyasına dâhil olma isteklerini ortaya çıkarmıştır. Sosyal medyanın tüm dünyaya erişmesi, bireylere duygu ve düşüncelerini ortaya koyabilecekleri bir platformda yansıtma fırsatı tanıması influencerların oluşumuna zemin hazırladı.

Televizyon üst sınıf ve yetenekli kişilerin ün kazanmasını gerçekleştirmekteydi. İnternetin yayılmasıyla beraber sosyal medya ile toplumu ünlü olma statüsüne 
katılmasını sağlamıştır. Sosyal medyanın insan odaklı yapısı, bireylerin kendilerini, yeteneklerini, olağanüstü davranışlarını ve düșüncelerini ifade edebileceği bir mecradır. Siradan bireyler de sosyal medyada kendini tanımlarken sosyal medya fenomeni, blogger ve influencer olarak kendilerini nitelendirmektelerdir (Çaycl, 2019). Sosyal medya sayesinde insanların internete olan yatkınlığı, bireylere yeteneklerini yansıtabilecekleri, duygu ve düşüncelerini paylaşabilecekleri ve karşılığında geri bildirim alabilecekleri bir mecra sunmuștur.

Sosyal medyayla beraber "influencerlar" takipçilerin yaşamlarının bir parçası haline gelmişlerdir. Influencerın Türkçe anlamı "etkileyici" olarak ifade edilmektedir. Influencerın günümüzdeki kullanımı "fenomen, nüfuzlu, kanaat önderi" şeklinde de tanımlanmaktadır. Etkileyiciler, geniş takipçi kitlesine sahip olan, takipçilerini ürün satın almaya yönlendiren, , yemek, seyahat, film, moda, spor, kozmetik gibi farklı ilgi alanlarında bilgi ileten kişilerdir (Aktaş \& Şener, 2019, s. 405; Karadeniz, 2019). Influencer çeşitleri ve özellikleri; influencerlar Makro, Mikro, Mega ve Nano Influencerlar olarak dörde ayrilır (Aydın Aslaner \& Aydın, 2021, s. 33).

Nano Influencer: \pm 1000 civarında takipçisi olan bireylerdir. Bu bireyler hizmet veya ürünle ilgili önerisini çoğunlukla arkadaşına tavsiyede bulunur tarzda gerçekleştirmektedir.

Mikro Influencer: $\pm 50,000$ civarında takipçisi olan bireylerdir, fakat hedef kitleleriyle aralarındaki iletişimin daha kuvvetli olduğu ve tüketicinin sosyal medya grafiğinde bizzat etkili olan bireylerdir.

Makro Influencer: sosyal medya aracılığıyla milyonlarca takipçiye hitap ederek kendi başarılarıyla hedef kitlesi tarafından takdir edilen, pazardan yüksek sponsorluk ücreti almayı talep edebilen ve takipçilerinin özellikleri ve eğilimleri konusunda detaylı bilgisi olmayan bireylerdir.

Mega Influencer: toplumda star olarak tanınan, 1 milyondan fazla takipçiye sahip bireylerdir. Ünlü sporcular, pop şarkıcıları, film yıldızları bu kategoride yer alır. Son zamanlarda gittikçe talep gören Mega Influencerlar, kullanıcıların satın almaya yönelik özendirici etkileri büyüktür.

Farklı insanların düşüncelerine nüfuz ederek, bakış açısını yönlendirebilir, kitlelere liderlik yapabilir niteliğine eriştiğinde influencer oluşmuş demektir (Zietek, 2016). Davranışlar; kişileri destekleme, takip etme isteği oluşturma, merak uyandırma, medya bağımlılığını oluşturmaktadır. Bu davranışlar sosyal, psikolojik ihtiyaçlarını karşılamak amacıyla sosyal medyayı deneyimlemekte ve kişilerde oluşturduğu doyuma göre farklılaşmaktadır (Sheldon, 2008). Influencerlar sosyal ve psikolojik olarak hedef kitleyi yönlendirme konusunda uzmanlaşmış olmaları pazarlama alanında ürün satın almaya yönlendirmede uzman kişilerdir.

Influencerlar hayat tarzlarını sosyal medya üzerinde yansıtmada yeteneklilerdir. Öte yandan, marka destekçileri olarak çalışırlar ve markaları tanıtmak için kanallarında dağıttıkları içerikleri oluştururlar. Bundan dolayı influencerlık sadece bir hayat tarzı sergilemesi değil, aynı zamanda 21. yüzyılın önde gelen popüler mesleğidir (Szczurski, 2017). Influencerların takipçilerini etkilemesi, işletmelere influencerların takipçilerine ulaşabilecekleri bir fırsat sunmaktadır. Ayrıca firmalar düşük maliyetle kolaylıkla daha fazla tüketiciye ulaşabilmektedir (Genç \& Kayalar, 2017, s. 655). Bu sayede firmalar ürün tanıtımı ve ürünlerin pazarlamasını hızlı ve düşük maliyetle sağlamaktadır. Firmalar yüksek miktarda reklam ücretinden tasarruf ederken aynı zamanda influencerlar ile 
milyonlarca tüketiciye ulaşmaktadır. Influencer kavramı, halkın içinden bir birey olmak ve somut görüşlerini tüketicilerle paylaşım yapmayı gerektirmektedir.

Influencerların takipçileriyle paylaştığı ürün pazarlamasında natürel, şeffaf ve samimiyet oldukça önemlidir. Influencerler takipçilerinin güvenini zedelemesi ile imajı sarsacaktır. Bundan ötürü influencerların daima ürünlere dair şeffaf bilgileri iletmeleri gerekmektedir (Eyel \& Şen, 2020, s. 26). Influencer için en önemli ana kavram kaliteli ve doğru paylaşımda bulunmaktır.

Bireylerin sosyal medya mecrasını aktif kullanma sebepleri; bilgi paylaşımında bulunmak, sosyal medya ağlarını kullanmak ve gelişmeleri takip etmek, eğlenerek güzel zaman geçirmek, internet üzerinden ürün satın almak, çeşitli araştırmalar yapmak, sanal oyunlar oynamak ve sosyal arkadaş edinmek amaçlı kullanılmaktadır (Bayuk \& Aslan, 2018; Fettahlıŏlu \& Çinkay, 2017; Mert, 2018). Sosyal medyanın kullanım yoğunluğu incelendiğinde, kullanıcılar vakitlerinin büyük çoğunluğunu sosyal medyada harcamaktadır.

Sosyal medya mecrasında kullanıcıların içerik oluşturmaya dâhil edilmesiyle yemek, seyahat, film, moda, spor, kozmetik konularında yapılan öneriler hızla yayılmıștır (Mert, 2018; Karadeniz, 2019). Influencerlar ilgi alanları yönünde tavsiyede bulunmaları kullanıcıların ilgisini çekmektedir. Kullanıcılar influencerın tavsiyelerine göre tercihlerini yönlendirmektedir.

Tablo 1. Geleneksel ve Sosyal Meydanın Karşılaștırması

\begin{tabular}{|l|l|}
\hline Geleneksel Medya & Sosyal Medya \\
\hline Kalıcıdır. & Güncellenebilir. \\
\hline Yorumlar kısıtıdır ve eş zamanlı değildir. & Yorumlar kısıtlama yoktur ve eş zamanlı yapıllabilir. \\
\hline Sınırıdır, geri dönüşüm gecikmeli olarak ölçülür. & Anlık olarak popülerliği ölçülebilmektedir. \\
\hline Arşivlere zayıf ve zor erişilir. & Arşivlere kolay erişebilir. \\
\hline Sınırlı medya karması bulunur. & Tüm medya karma hâle getirilebilinir. \\
\hline Organizasyonlar tarafından yayımlanır. & Bireysel yayımcılık vardır. \\
\hline Belli bir yere kadardır ve sınırlıdır. & Sınırsızdır. \\
\hline Paylaşımlar için teşvik edilmemektedir & Paylaşım ve katıım teşvik edilir. \\
\hline Denetimlidir. & Özgürlükçüdür. \\
\hline
\end{tabular}

Kaynak: Stokes, 2013: 366.

Tablo 1'de geleneksel medya ve sosyal medya özelliklerinin karşılaştırılması yapılmıştır. $\mathrm{Bu}$ karşılaştırma ile sosyal medyanın geleneksel medyaya göre daha esnek ve kolay erişilebilir olduğu görülmektedir. İçerikler bakımından sosyal medyanın geniş kapsamlı olması sonucunda kullanıcıyı daha çok sosyal medya kullanımına teşvik etmiştir. Bu kapsamda reklam verenler ve firmalar sosyal medyada ürün tanıtımı yapmayı daha fazla kullanıcıya ulaşmak için tercih sırasında öne almaktadır.

Reklam verenler/markalar sosyal medyayı önemli bir reklam mecrası olarak değerlendirmekteler. Etkileşimle şekillenen yeni reklam algısı için influencerların takipçileriyle oluşturdukları duygusal bağ, reklam imkânları tarafından gerekli koşulları hazırlar (Aslan \& Ünlü, 2016). Influencerlar takipçileriyle kurdukları duygusal bağı ile ürettikleri içerik paylaşımlarını şekillendirmektedir. Kullanıcılara yansıyan samimi duyguların hissettirilmesiyle markalar tarafından ürün pazarlamasında influencerlardan faydalanılmaktadır. 
Sosyal medyada karşılıklı iletişimin yoğun olması sayesinde ürünler hakkında tüketiciler hızlıca bilgilenmektedirler. Sosyal medya üzerinden pazarlama hem marka imajını kuvvetlendirmekte hem de ekonomik olarak maliyeti düşürmektedir (Yanar \& Yllmaz, 2017). Sosyal medyada ürünlerin direk satışı yapılarak mağaza kirası, mağaza çalışan ücreti, reklam ücreti vb. maliyetlerin azalmasını sağlamaktadır. Bundan ötürü markalar direk fabrikadan satış ile birçok maliyet düşürüldügü gibi firmanın kâr oranının artmasını sağlamaktadır.

Influencerın oluşturduğu bağ ve güvenirliği tüketicilerin influencerlarla iletişim sürecinde önemlidir. Influencerların tüketicilerin satın alma isteğini olumlu yönde etkilemektedir (Aydın Aslaner \& Aydın, 2021). Makalede özellikle influencer ile takipçileri arasındaki bağ ve güvenilirlik konuları araştırılmaktadır. Bunun arttırılmasına yönelik stratejiler ortaya konmaktadır.

Influencerların pazarlama alanına girmesi sonucu, etkileyici pazarlama ve potansiyel alıcılar üzerinde yönlendirme yapma gücü olan kişilerdir (Xiao, Wang, \& Chan-Olmsted, 2018). Özellikle sosyal ağların en popüler alanı olan Instagramda influencerlar vasıtasıyla birçok markanın ürün ve hizmet tanıtımı yapılmaktadır (Özgen, 2012). Influencerlar için en fazla kitleye ulaşabileceği Instagram'da hedef kitle oluşturarak takipçilerine kendilerini tanıtırken güçlü bir lider profili oluşturmayı hedeflemektedirler.

Markaların ürün tanıtımı ve reklamının yanında mesaj politikasıyla sosyal medyanın ayırt edici özelliğiyle etki faktörleri (örn. beğenmek, müşteri yorumu, etiketleme) arasında ki uyum incelenmektedir. Influencerlar ürün yerleștirmesi ile takipçilerini ürünün sayfasına yönlendirip, ürün pazarlamaya yönelik takipçileri daha çok alışveriş yapmaya teşvik etmektedir (Aktaş \& Şener, 2019; İşlek, 2012). Sosyal medyada yapılan paylaşımlar kullanıcıların satın alma davranışlarını olumlu yönde etkilediği gibi markanın tanınırlığını da sağlamaktadır (Karabakan, 2020). Influencer bir taraftan marka tanıtımı yaparken, diğer taraftan takipçilerinden gelen geri bildirimlere yönelik aksiyon almaktadır._

Influencer pazarlaması, reklam verenler ve markaların hedef kitlelerinin kullandığı sosyal medya mecralarında gözükmek ve onlarla iletişim kurmak için geliştirilen dijital pazarlama şeklidir. Hedef kitle bakımından en doğru içerikleri oluşturmaları gerekmektedir. Marka ile uyumlu, modern içerikler ile hedef kitlenin kısa sürede satın almaya ikna edilmesi sayesinde markaya bağlılı̆̆ arttırmaktadır. Bunun sonucunda marka kendisini influencer pazarlama ile sektörde ön sıralarda saf tutan firmalar arasında bulunacaktır (Köse \& Çakır, 2019, s. 218). Firmaların markalaşma hedeflerine giden yolda, influencerlar en büyük destekçileri olmaktadır.

Pozitif etkili bir marka yüzü oluşturmak için, influencer pazarlaması yanında ürünün satış fiyatının oluşturulması, hikâyenin etkileyiciliği ve hedef kitlenin sınırlarının çizilmesi gereklidir (Gönülșen, 2020, s. 29-31). Sosyal medya mecrası sayesinde reklam veren/ üretici firma, influencerı takip eden kullanıcılar ve influencer birlikteliği oluşturup, pazarlanan ürünleri kolaylıkla satın alabilmekte ve firmaya kolayca ulaşabilmektedir. Sonuç olarak reklam veren ve üretici firma influencerın etkileşimine pozitif katkı sağlamaktadır (Ulaş \& Alkan, 2020, s. 111). Firma ve influencer uyumu ile etkileyici içeriklerle hedef kitlenin ürün alma isteklerini arttırması beklenen sonuçtur._

Firmanın influencerdan faydalanarak kazanç elde edebilmesi için derinlemesine araştırma yapması ve strateji belirlemesi gerekmektedir. Markayı temsil edecek olan influencer takipçi sayısı, takipçileriyle oluşturduğu ilişkiyi değerlendirmesi ve hitap ettiği kitlenin 
maddi imkânları dikkate alınmalıdır. İşbirliği yapılan influencerın nasıl ürünü daha etkili pazarlayabileceği ve takipçilerinin hangi tür ürünlerin ilgisini çekeceği araştırılmalıdır (Canöz, Gülmez, \& Eroğlu, 2020, s. 89). Sosyal medyanın halkla ilişkiler ve pazarlama alanlarına katkısı büyük olmakla beraber çeşitli çekinceler de bulunmaktadır. Kişilerle iletişim eksikliği, ilgi çekecek içeriklerin üretilmesinde zayıflık, yanlış algı oluşturma durumları ve yapılan olumsuz yorumlar markaların imajlarını zedeleyebilmektedir (Kılınç, 2020, s. 19). Bunların önüne geçebilmek adına iletişim, beğeni ve yorum konularına hassasiyetle yaklaşılması gerekmektedir.

Türkiye'de influencer pazarlama artık sektörleşmektedir. Bunun bir göstergesi de influencer pazarlama ajanslarının oluşmasıdır. Bu organizasyonlar, markaları influencerları ve içerikleri buluşturmaktalar (Kır \& Öztürk, 2020, s. 44-46). Influencerlık Türkiye'de yıldızı parlayan, geleceğin en gözde mesleklerinden biri olarak karşımıza çıkmaktadır. $\mathrm{Bu}$ alanda yapılmış ve yapılacak çalışmalar, influencer mesleğine adım atacak olanlar için kılavuz niteliği taşımaktadır.

\section{Yöntem}

Nitel araştırma metodu olan yarı yapılandırılmış mülakat görüşme tekniği ile sosyal medya kullanıcılarının takip ettikleri ve takibi bıraktıkları influencer üzerine duygusal ve sosyal deneyimlerini içeren görüşmeler yapıldı. Araştırma soruları kullanıcıların influencerları takip etme ve bırakma eğilimine yönelik duygularına ulaşma hedefiyle oluşturulmuştur. Araștırma sorularına alınan yanıtlar sonucunda toplanan veriler, profesyonel meslek sahipleri ve işyeri sahipleri ve öğrencilerle yüz yüze görüşmeler yapılarak toplandı._

Tablo 2. Araştırma Soruları

\begin{tabular}{|l|}
\hline Giriş \\
\hline Takipte olduğunuz influencer \\
\hline $\begin{array}{l}\text { Kişisel gelişiminize katkısı açısından örneklerle değerlendirir misiniz? } 10 \\
\text { üzerinden notlar mısınız? (10 kişisel gelişime katkısı yoğun) }\end{array}$ \\
\hline $\begin{array}{l}\text { Satın almayı düşündüğünüz mal/hizmetlere katkısı açısından saf ticari ve/veya sadece yol gösterici } \\
\text { olmasını örneklerle değerlendirir misiniz? } 10 \text { üzerinden notlar mısınız? (10 yol gösterici) }\end{array}$ \\
\hline $\begin{array}{l}\text { Kendisini paylaşımlardan size doğal ve/veya yapay gelen noktaları örneklerle } \\
\text { değerlendirir misiniz? } 10 \text { üzerinden notlar mısınız? (10 şeffaf) }\end{array}$ \\
\hline Takibi bıraktığınız (fiilen bırakmamışta olabilir) influencer \\
\hline $\begin{array}{l}\text { Kişisel gelişiminize katkısı açısından örneklerle değerlendirir misiniz? } 10 \\
\text { üzerinden notlar mısınız? (10 kişisel gelişime katkısı yoğun) }\end{array}$ \\
\hline $\begin{array}{l}\text { Satın almayı düşündüğünüz mal/hizmetlere katkısı açısından saf ticari ve/veya sadece yol gösterici } \\
\text { olmasını örneklerle değerlendirir misiniz? } 10 \text { üzerinden notlar mısınız? (10 yol gösterici) }\end{array}$ \\
\hline $\begin{array}{l}\text { Kendisini paylaşımlardan size doğal ve/veya yapay gelen noktaları örneklerle } \\
\text { değerlendirir misiniz? } 10 \text { üzerinden notlar mısınız? (10 şeffaf) }\end{array}$ \\
\hline Size sormam gereken ama sormadığım bir şey kaldı mı? \\
\hline
\end{tabular}

\subsection{Araştırma Evreni ve Örneklem}

Araştırmanın evrenini sosyal medya kanalı olan instagramda influencerları takip eden kişilerden oluşmuştur. Instagram'a odaklanılmasının sebebi influencerların takipçilerle en yoğun ilişki yaşadığı mecradır (Ishani, 2019). Etnografide davranış ve ardındaki sebep araștırıldığından, örneklimi oluştururken hedef kitle sadece Instagram'da influencerları takip etmiş ve bırakmış takipçilerdir (Young, 2015). Katılımcılar arasında takip ettikleri influencerlar arasında çeșitlilik oluştursa da araştırma konusu olan takip veya bırakma kararı davranışsaldır. Amaç mülakat sonucu elde edilen çıkarımlardan örüntüler elde etmektir (Young, 2015). 2021 yılında, Instagram'da aktif, daha önce influencer takip 
etmiş ve bırakmış 16 kişiyle derinlemesine mülakat yapıldı ve takip edilen ve bırakılan influencerlar ile ilgili kullanıcı deneyimleri araştırıldı. Olumlu duygular; kişisel gelişim, yönlendirme, şeffaflık, olumsuz duygular; yoksunluk, haksız ticari faaliyet, sahte gösterişli hayata göre soruldu.

Şekil 3'de kullanıcıların influencer takibine yönelik olumsuz izlenimleri; yoksunluk, ticari faaliyetin oluşturduğu kötü ürün tanıtımı, sahte ve gösterişli yaşam tarzını yansıtmaktadır. Olumlu izlenimleri ise kişisel gelişime katkı sağlama, kaliteli ürün tanıtımı, şeffaf samimi ve içten davranış sergilemeleridir.

Tablo 3. Kullanıcıların Hissettikleri Olumlu/Olumsuz Influencer İzlenimleri

\begin{tabular}{|l|l|}
\hline Olumsuz & Olumlu \\
\hline Yoksunluk & Kişisel gelişim \\
\hline Ticari & Yönlendirme \\
\hline Sahte & Şeffaflık \\
\hline
\end{tabular}

Tablo 4 incelendiğinde kullanıcıların takip etmekte ki seçicilikleri ön plana çıkmaktadır. Kullanıcıların takipten faydalandığı ve keyif aldıkları konular sağlık, beslenme, yemek, teknoloji moda, kozmetik, takı tasarım, spor ve gezi alanlarındır. Bu alanlarda kullanıcıların takip ettikleri ve takibi bıraktıkları influencerlara kişisel gelişime katkısı, yol göstericiliği ve şeffaflığı üzerinden puanlamalar yapmaktadır.

Tablo 4. Influencerların İlgi Alanları, Takip Edilen ve Bırakılan Influencerlar

\begin{tabular}{|l|l|c|c|c|}
\hline $\begin{array}{l}\text { Takip Edilen } \\
\text { Influencerlar }\end{array}$ & İlgi Alanı & $\begin{array}{c}\text { Kişisel Gelişime } \\
\text { Katkısı }\end{array}$ & Yol Göstericiliği & Şeffaflığı \\
\hline K/32 & YEMEK & 10 & 10 & 10 \\
\hline E/36 & SAĞLIK & 9 & 7 & 10 \\
\hline K/25 & TEKNOLOJi, TANITIM & 9 & 10 & 2 \\
\hline K/22 & UZMAN PSIKOLOG & 9 & 10 & 9 \\
\hline E/23 & EĞLENCE VE GEZi & 8 & 3 & 8 \\
\hline K/22 & ÇOCUK DOKTORU & 9 & 7 & 7 \\
\hline E/36 & YEMEK & 10 & 8 & Şeffaflığı \\
\hline Takibi Bırakılan & Influencerlar & İlgi Alanı & Kişisel Gelişime & 0 \\
\hline E/23 & TAKI TASARIM & 7 & 4 & 2 \\
\hline K/25 & TAKI TASARIM & 5 & 1 & 0 \\
\hline K/32 & MODA, KOZMETiK & 2 & 2 & 2 \\
\hline E/21 & MODA VE GEZi & 3 & 4 & 1 \\
\hline K/22 & MODA VE KOZMETiK & 2 & 3 & 0 \\
\hline E/23 & SPOR & 3 & 4 & 2 \\
\hline E/36 & AYAKKABI FiRMASI & 3 & 4 & 0 \\
\hline K/32 & MODA VE TAKI & 1 & 2 & \\
\hline
\end{tabular}

\section{Etik Kurul İzni}

Erzincan Binali Yıldırım Üniversitesi İnsan Araştırmaları Etik Kurulu'nun 27.01.2021 tarih ve 02-04/02-08 sayılı kararları çerçevesinde çalışma etik açıdan bir sakınca içermemektedir. 


\section{Bulgular}

Mülakatlar sonrasında açığa çıkan bulgulara yönelik yapılan analiz sonucunda 3 ana başlık altında (gelişim, amaç ve gerçeklik) ikişer tane kavramla ortaya çıkmaktadır. Alt başlıklarda kişisel gelişimde motive edici ve aydınlatıcıdır. Yoksunlukta yüzeysel ve hegemonyacıdır. Faydalı üründe yönlendirici ve seçicidir. Ticari üründe aldatıcı ve marka odaklıdır. Şeffaflıkta samimiyet ve kendisiyle barışıktır. Sahte hayatlarda manikür hayat ve şişirilmiş ego kavramları öne çıkmaktadır.

Mülakatlarda kullanıcının takip ettiği veya takibi bıraktığı influencer kendisinin belirtmesi üzerine bilgileri araştırmacı tarafından toplandı. Mülakatlarda elde edilen influencer kimlikleri çalıșmaya dâhil edilmemektedir. Araştırmacı tarafından influencer ve katılımcı kişisel bilgileri gizli tutulacaktır.

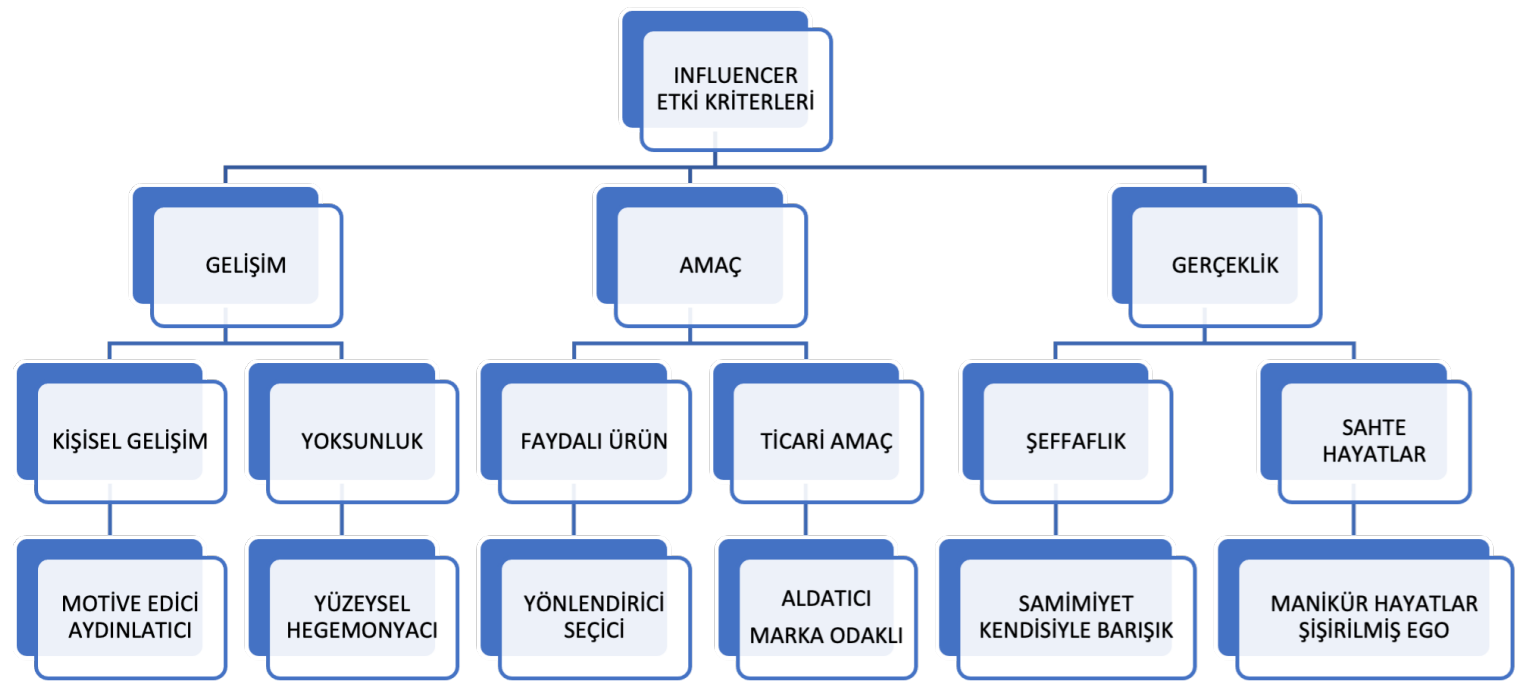

Şekil 1. Influencer Etki Kriterleri

\subsection{Gelişim; Kişisel Gelişim ve Yoksunluk}

Gelişimde yoksunluk ve kişisel gelişime katkısı açısından mülakat sonuçları değerlendirildiğinde kullanıcıların kişisel gelişime katkı sağlayan influencerları olumlu olarak puanladıkları (Kişisel gelişime katkısı:10 olarak puanlamaktayım- K/28) ve kișisel gelişime katkısı olmayan influencerları takibi bıraktıkları ya da eskisi kadar takip etmedikleri görülmektedir.

Influencer motive edicidir. Kullanıcı takip ettiği influencer sayesinde yeteneksiz hissettiği bir konuda bilgi edinerek başarıya ulaşmaktadır Kullanıcı influencer tarafından harekete geçirilmektedir: Nefis yemek tarifleri ile birçok yemeğin, tatlının ve kolay atıştırmalıkların tarifine ve püf noktalarına ulaşabilir ve yapabilirim. Baklava yapamam sanıyordum açtım tarifi bir güzel anlatmışlar ve gerçekten sonuç olarak yapabildim çok faydalı tavsiye ederim (K/32). Eğitime olan düşü̈nlüğü sürekli araştırması okuması ve bunları paylaşıp yol gösterici olması benimde motive olmamı sağlıyor. Paylaştığı romanlar, kitap seçimimde çok yardımcı oluyor. Sağlıklı beslenmesi, bu yönde tarifler paylaşması olumlu bir izlenim bıraklyor ve beslenmeme dikkat etmemi sağliyor (K/28).

Influencer aydınlatıcıdır. Kullanıcı teknoloji konusunda bilgiler kazandığı için kişisel gelişimine katkısı olduğunu hissetmektedir: Elektronik alanında tüketim yaparken karar verme aşamasında ve ürünlerin özelliklerini anlama konusunda katkıda bulunuyor. 
Elektronik aletler hakkında bilgi sahibi oluyorum. Bilmediğim birçok özellik olduğunu takip ettikten sonra fark ettim (K/25).

Yoksunluk hissini ön planda hissettiklerinde puanlamaları çok düşmektedir (Kişisel gelişime katkısı: 3 olarak puanlamaktayım-E/32).

Takibi bırakılan influencerın bilgilendirmesi önemsiz ve yüzeyseldir. Hayatın derin anlamını sağlamamaktadır. Paylaşımların önemli olmadığı zamanla görülmektedir. Takı ve giyim konusunda ilham olmasından kaynaklı takip etmekteydim. Hayatta çok daha önemli ve değerli duygular olduğunu anladım bu süreçte, virüs sebebiyle kullanamayacağım takılara bakmamın, satın almanın gereksiz olduğunu düşündüğüm için eskisi kadar takip etmiyorum (K/25).

Influencerın paylaşımcı olmayan, tek yönlü, hegemonyacıya bir ilişki kurmaya başladığında takipçiler ayrılmaktalardır. Hikâyeyi göstermek yerine kendisini ön planda tutması yadırganmaktadır. Makyaj, moda konulu paylaşımlar vaat edip hayatının her ayrıntısı paylaşmaya başlaması kendisine karşı antipati oluşturdu. Özellikle saygısız tavırları ve gereksiz boş konuşmaları sıkılmama neden oldu. Ürün tanıtma konusunda bence yetersiz. Sadece kendisini ön planda tutmaya çalışıyor. Başlangıçta pozitif enerjisi ve sağlıklı tarifler paylaşması ile takibe aldım. Ancak üstümde çok etkisinin olduğunu düşünmüyorum. Zamanımı boşa harcadığımı fark ettim (E/32). Makyaj videoları paylaşmakta fakat artık hiç ilgimi çekmemeye başladı, Virüs nedeniyle de artık makyaja gerek duymuyorum. Kişisel gelişime katkısı olmadığı kanaatindeyim. Sadece kendini gösterişli hayatını anlatıp duruyor, artık kendisini sıradan ve sıkıcı buluyorum (K/32).

\subsection{Amaç: Faydalı Ürünlere Yönlendirme ve Ticari Amaç}

Influencerın amaç odaklı paylaşımda bulunması kullanıcıların takip etme ve takibi bırakma konusunda yaklaşımlarını incelediğimizde; saf ticari amaç kullanıcıyı rahatsız etmekte ve takibi bırakmalarındaki en önemli kriterdir. Yol gösterici influencerlar ise kullanıcıya olumlu deneyim kazandıran tanıttığı ürünün arkasında durabilen ve kullanıcıyı doğruya yönelterek, kullanıcının takip ederken keyif almasını sağlamaktadır. Takipçiye hissettirmeden yapmaktalar (Ticari amacı yok. Illa ki var ama diğer insanlar gibi değilK/22). Yüksek puan almaktalar (Ticari amaç açısından 8 olarak puanlamaktayım-E/36).

Başarılı influencerlar yönlendiricidir. Ürünler ve servislerde doğru yönlendirmenin kullanıcıyı memnun etmektedir. Ürün tanıtırken negatif ve pozitif yönleri paylaşmak güven artırmaktadır. Tarifler o kadar güzel hazırlanmış ki evdeki malzemene göre tarif bulup yapabiliyorsun. Ayrıca deneyenlerin yorumları da oldukça fikir sahibi olmanızı sağliyor. Uygulamasına yönlendirmede bulunuyor ve kesinlikle yol gösterici sizi direk tarife yönlendirmesi kısa zamanda kolaylıkla ulaşmanızı sağlıyor (K/32).

Takipçileriyle samimi ilişki kuran influencerlar pazarlama yapacakları üründe seçicidirler. Seçimlerinde kendilerinin arkasında durdukları, misyonlarına uyumlu, kendilerinin de kullandıklarından oluşmaktadır. Tanıtım yapılan ürünlerde tutarlılık olması, her ürünün değil ama influencer-takipçi arasındaki kurulan bağa uygun seçimler yapılmaktadır. Reklamını yaptı̆̆ı ürünlerin belli bir standardı yok her ürünün tanıtımını yapıyor. Kıyafet konusunda tanıtımları bazen yol gösterici olabiliyor (K/25). Çok fazla reklam paylaşımında bulunmuyor ara sıra yaptığı reklamlarda sadece yol gösterici ya da özellikle kadın girișimcilerin yaptığı ürünlerin destek için tanıtımını yapıyor (K/25). İnsan sağlığına katkı sağlayacak ve kolay ulaşılabilir, ticari bir amaç gütmeden paylaşım yapmaktadır. 
Kilo vermek için ve B12 vitamin eksikliğinin giderilmesi üzerine paylaşımlarından çok faydalandım (E/36).

Saf ticari amacı gözettiği düşünülen influencerlar aldatıcı ve marka odaklı olmakla yargılanmaktalar (Yol göstericiliğini 2 olarak puanlamaktayım (K/25).

Aldatıcı bilgiler vermesi takipçiyi sinirlendirmektedir. Kendisinin arkasında durmadığı ve kullanmadığı ürünü tanıtması ticari bulunmaktadır. Benzer satışyapanlarla kıyasladığımda ürünlerin fiyatı pahalı olup, rekabet ortamına uyum sağlayamamaktadır. Ürünü tanıttığı kadar kaliteli olmaması nedeniyle yol gösterici bulmamaktayım anlattığı ürün farklı temin edilen farklıdır (E/36). Ticari amaca fazla odaklanması beni rahatsız ediyor. Kolyeleri övüyor. Ürünleri çok pahalı. Sadece Beşiktaş için alın diyor (E/23). Başta yaptığı makyaj tanıtım işiyle hiç ilgisi yok birçok ürün pazarlamasını yaparken kullanmayacağı ürünleri övmesi sinir bozucu. (K/22). Paylaşım yaptıkları ürünlerin anlattıkları gibi gelmemesi ve konforlu dedikleri ürünlerin rahatsı edici olmasından kaynaklı șeffaf olmadıklarını hissettirdiği için takipte olmama karşın ilgimi çekmiyor (E/36). Kalitesiz ürünlerin bile reklamını yapıyor $(K / 22)$.

Marka odaklı düşünmede, konu takipçilerden, bağdan, samimiyetten ayrılıp, marka için iyi olana dönüşmesi takipçileri uzaklaştırmaktadır. Yemekle ilgisi de olmasa lüks marka olması ön plandadır. Büyük markalarla flörtleşmektedir (K/36).

\subsection{Gerçeklik; Şeffaflık ve Sahte Hayatlar}

Influencerların gerçeklikten uzak yapmacık tavırları kullanıcılar tarafından kolaylıkla anlaşılabilmektedir. Sahte yaşam tarzlarının gösterilmesi, şeffaf olmayan tutumlar, yalnız takipçi sayısını arttırmak için yapılan kurgular kullanıcılar tarafından influencerlara olan güveni zedelemektedir.

Kullanıcılar daha samimi ve şeffaf olan influencerları takip etmekte ve aralarında güçlü duygusal bağ kurmaktalar (Şeffaflık 10 olarak puanlamaktayım-K/25).

Samimiyet takipçilerle ilişkiyi sağlamlaştırmaktadır. Doğal paylaşımlarda bulunuyor. Sürekli mutlu gözükme çabasında değil. Şeffaf davranıyor. (K/25)

Kendisiyle barışık olması, gülünç durumlarını nükteli anlatması, hatalarını anlatması, başkalarının dediğine göre davranmaması kuvvetli bir çekim oluşturmaktadır. Kendisiyle barışık, şeffaf. Ona gelen hediyelerin tanıtımları şüpheyle karşılanmıyor. Kendisine gelen soruları (yemekten ev dekorasyonuna) cevapliyor (K/36).

Kullanıcılar doğru orantılı olarak samimi ve şeffaf olmadıklarını hissettikleri influencerları takip etmeyi bırakmaktalardır (Şeffaflıkta 1 olarak puanlamaktayım (K/22)).

Manikür hayatlar takipçileri rahatsız etmektelerdir. İkiyüzlü tavırları, takipçilerine yansıttıkları yaşam tarzı ile gerçekte olan yaşam tarzlarının farklı olması, influencerların şeffaf davranmaması kullanıcılarda güven eksikliği oluşturmaktadır. Yapay geliyor. Çünkü sayfasında başlangıçtaki gibi paylaşımlar yapmıyor sürekli kendinden ve hayatından bahsediyor. Kendi kullanmadığı ürünlerin bile tanıtımı yaptığı çok belli (K/25). Her gün farklı bir kolye ile görmek gerçekçi değil. Şeffaflık; 0 olarak puanlamaktayım (E/23).

Şişirilmiş ego samimiyetsiz bulunmaktadır. Aşırı bir özgüvene sahip olunduğunda takipçi rahatsız olmaktadır. Tavırları ve konuşmaları tamamen yapay, makyaj ürününe o kadar değişik ifadeler kullanıyor ki sanki atomu bulmuş gibi abartıyor, tek amacı gösteriş yapmak, 
en iyi yerlerde gezip tozuyorum havasinı atmak. Samimiyetsiz tavırlarından sıkıldım. $(K / 25)$.

\section{Tartışma ve Sonuç}

Günümüzde dijital dünyanın gelişmesiyle birlikte sosyal medya fenomeni, blogger, youtuber ve influencerlar (sosyal medya etkileyicisi) meydana çıkmıştır. Sosyal medya platformları ile milyonlarca kişiyi birleştirmiş, farklı görüş, bilgi ve tecrübelerin paylaşılmasına zemin hazırlamıştır. Influenceları takip etmekten amaç bilgi almaktadır. Burada hangi bilgiyi ne amaçla ve nasıl sunduğu ayırt edicidir. Gereksiz bilgiyi satış amaçlı ve kendini ön plana tutarak sunduğunda takipçiler tepki göstermekteler. Dijital pazarlama yöntemlerinin, markalar için büyük önem taşıdığına vurgu yapmak gerekmektedir. Çünkü markanın pazarlama alanının gözdeleri influencerların hedef kitleye ulaşması, satın alma eğilimine yönlendirmesiyle markaların kazancını artırmaktadır.

Bilgiyi kişileştirilmiş haber kanalı gibi bilgilendirmelidir. Takipçinin ilgili olduğu bir alanda aydınlatıcı olmalıdır. Mülakatlara katılımcılar yemek/gurme, sağlık, teknoloji, psikoloji, eğlence, gezi, tıp, moda alanlarında influencerları takip etmekteler. Konu dışına çıktığında takipçilerin tepki çekmekteler. İlgi alanı kesiştikten sonra, takipçilerin influencerları yoğun takip etmedeki faktör motivasyondur. Takipçinin başarmaktan zorluk çektiği bir konuda influencer bilgi eksiğini gidererek doğru davranışı sergilemesini sağlamaktadır. Takipçiyi başarmak istediği bir konuda motive etmesi bağı kuvvetlendirmektedir.

Ürün tanıtımı ilgi alanında seçici ve motivasyonu destekleyici șekilde yol gösterici olmalıdır. Satıcı gibi davrandığında, markayı öncelediğinde takipçiler bunu sezmekteler. Önce takipçiler için neyin iyi olduğunu sorgulayarak ürünü seçmelidir. Arkasında durmadığı, kendi deneyimin bir parçası olmayan ürünün tanıtımı yapmamalıdır. Ürünü influencerın doğal bağlamına yerleştirildiğinde takipçiler bir pazarlama kurgusu içinde olduklarını anlamamaktalar.

Influencer bilgiyi ve ürünü şeffaf şekilde göstermelidir. Influencer ticari amaçla yapsa da, bunu samimi ilişkiye, dürüstlüğe gölgelemeden yapmalıdır. Manikür hayatlar ilk bașta ilgi çekse de, takipçiler bir süre sonra sahte hayatlardan uzaklaşmaktalar. Her zaman gülen insanlar, hiç bitmeyen eğlence, hep şık kıyafetler takipçileri sorgulatmaktadır. Influencerların yansıttığı yaşam biçimleri, özendirme ve sahtelik üstüne inşa edildiğinde kullanıcıları kendilerinden uzaklaştırırken, aksine ürün pazarlaması yaparken şeffaf ve yol gösterici olmaları sonucunda takipçi sayısını arttırmaktalar.

Bütün bunlar bir zincirin halkası gibi birbirlerine bağlantılıdır. Sahte yaşam tarzını göstermeleri kişilerde yoksunluk hissettirirken, ticari faaliyet nedeniyle kalitesiz ürün pazarlaması yapmaları kullanıcıyı influencerdan soğutmaktadır. Kalitesiz ürünün eksiklerini iletmemeleri şeffaf tutum sergilemedikleri için kullanıcının takibi bırakmasına yol açmaktadır. Sahte hayat tarzını yansıtan influencer, kullanıcıların kurgu yaşamların sıkıcılığını hissetmesine yol açmaktadır.

Özellikle influencer başarıyı yakaladıktan sonra (yüksek miktarda takipçi sayısı ve takipçileriyle yoğun iletişim) kesişim konuları ve samimiyeti yerine kendini ön planda tutması yaşanmaktadır. Şişirilmiş egosuyla artık her kare kendisini göstermektedir. Hâlbuki hata yapmanın öğrenmenin bir parçası olduğunu takipçilerine kendi hayatından sergilemesi, kendisiyle barışık olarak yaşaması çok olumlu etki yapmaktadır. Yapılan mülakatlardan birinde katılımcı takip ettiği influencerdaki değișimi anlatmaktadır. Makalenin göstermiş olduğu analiz çerçevesine bir influencerın olumlu uçtan olumsuz uça 
geçişi tablo 4'te gösterilmiştir. Katılımcı kafasındaki natürel imajdan, kesişim alanı olan yemek, moda, dekorasyon konularından çıkmasını işaret etmektedir. Artık profesyonel makyajlardan, kişisel kıyafetler yaptırmaktan, sürekli kendini çekmesinden, fotoğrafların üzerinde oynamasından moda ikonuna dönüşünden bahsetmektedir. Otantik doğal olmaktan imaja sahte yaşam kurmaya doğru akıştadır. Hatta katılımcı yolda görsem, tanışsam arkadaş olabileceğimi düşündüm demektedir. Kendisiyle özdeşlemesini şöyle ifade etmekte: Çok kafa dengi arkadaş olabileceğin, yakın, samimi, içten, anne, genç, annebabasıyla ilgili resimlerini koyuyordu (aynı zamanda kendisi bir çocuk), eşiyle fotoğrafları. Tüm rolleri görüyordum. Şimdi özel klyafet tasarlatan, arkadaşlarının ve çevresinin olmadığı sadece kendisi.

Tablo 4. Bir Influencerin Dönüşü

\begin{tabular}{|c|c|c|}
\hline & Eski hali- Samimi & Yeni hali-Ego \\
\hline Aydınlatıcı- Yüzeysel & $\begin{array}{l}\text { Ortak konumuz yemek pişirme ve } \\
\text { yemeyi sevmekti. İlgi alanımdan } \\
\text { olduğu için moda, dekorasyonla ilgili } \\
\text { paylaşımları hoşuma gitmekteydi. }\end{array}$ & $\begin{array}{l}\text { Moda ve kendisi ön planda } \\
\text { Yemek çok geride kaldı. }\end{array}$ \\
\hline Motive edici- Hegemonyacı & $\begin{array}{l}\text { Yaptıkları yemeklerde iyi ve kötü } \\
\text { olan, püf noktalarını paylaşıyordu. }\end{array}$ & $\begin{array}{l}\text { Özel kıyafetler tasarlanıyor } \\
\text { ve üstüne giymekte. }\end{array}$ \\
\hline Yönlendirici-Aldatıcı & $\begin{array}{l}\text { Ona gelen hediyelerin tanıtımları } \\
\text { şüpheyle karşlanmıyordu. Kendisine } \\
\text { gelen soruları (yemekten ev } \\
\text { dekorasyonuna) cevaplıyordu. }\end{array}$ & Artık kesişim konumuz kalmadı. \\
\hline Seçici-Marka odaklı & $\begin{array}{l}\text { Sadece kendi yaşam tarzına uygun } \\
\text { markaları göstermekteydi. Hatta } \\
\text { kullanıyordu ama tanıtmıyordu. }\end{array}$ & $\begin{array}{l}\text { Moda ikonuna dönüştü. Büyük } \\
\text { markalarla flörtleşmektedir. }\end{array}$ \\
\hline Samimi-Manikür hayatlar & $\begin{array}{l}\text { Eskiden makyaj yapardı } \\
\text { ama kendisi yapardı. } \\
\text { Arkadaşlarıyla olan ilişkileri ön plandaydı } \\
\text { Hangi restoranlara gitmişler ve } \\
\text { menüdeki ve ambiyansla ilgili görüşünü } \\
\text { söylüyordu. Gustoya oynuyordu. } \\
\text { Gündelikti, ev halinde görülüyordu. }\end{array}$ & $\begin{array}{l}\text { Şimdi profesyoneller } \\
\text { makyajını yapmaktalar. }\end{array}$ \\
\hline $\begin{array}{l}\text { Kendisiyle barışık- } \\
\text { Şişirilmiş egolar }\end{array}$ & $\begin{array}{l}\text { Kendisiyle barışık, şeffaf. } \\
\text { Natürel. Çok kafa dengi arkadaş } \\
\text { olabileceğin, yakın, samimi, içten, } \\
\text { aynı zamanda anne, genç, anne- } \\
\text { babasıyla ilgili resimlerini koyuyordu- } \\
\text { aynı zamanda bir çocuk- eşiyle } \\
\text { fotoğrafları. Tüm rolleri görüyordum. }\end{array}$ & $\begin{array}{l}\text { Arkadaşları artık resimlerde yok. } \\
\text { Koyduğu fotoğrafların üzerine } \\
\text { oynanıyor. Fotoğrafların renk } \\
\text { değişimi yapılıyor. Manken gibi } \\
\text { fotoğraflar koymaya başladı. } \\
\text { Moda ikonuna dönüştü. }\end{array}$ \\
\hline
\end{tabular}

Influencerlarla çalışmayı düşünen markalar/firmaların kullanıcıların tercihlerini dikkate alarak influencer tercihinde bulmalıdırlar. Markalar influencer seçerken; firmanın alanına uygun içerikler üretmesi ve liderliğini üstlendiği kitlenin satın alma isteklerini arttırma yönündeki etkisini gözlemlemesi gerekmektedir. Başarılı kampanyalarda, olumlu içerik oluşturan, uzun süredir ünlü ve takipçi sayısı fazla olan influencerın etkisi görülmüştür (Korotina \& Jargalsaikhan, 2016 ). Firmalar influencer seçiminde ürünün tanıtımı konusunda uzman, doğrudan kullanıcının algılama tarzını etkileyebilen ve kitleyi satın almaya yönlendirebilenle çalışmalıdırlar (Pugazhenthi ve Ravindran, 2013). Pazarlama yöneticileri, ürünlerinin lansmanı için influencer seçmeden önce dikkat çekiciliği ve uzmanlığı ile ilgili bilgileri göz önünde bulundurmalıdırlar (Rachbini, 2018). Kullanıcılar influencer tavsiyelerini dikkate alarak ürün satın almadan önce kullanıcı deneyimlerini öğrenmeleri ürün satın alma/satın almama tercihlerini etkilemektedir. Çalışmada firmalar ürünlerini tanıtmak için influencerı nasıl seçmesi gerektiği gösterilmiştir. $\mathrm{Bu}$ 
bağlamda, çalışmanın neticesinde, influencerın seçiminde şeffaflığı, yol göstericiliği ve kişisel gelişime olan katkısı dikkate alınmalıdır.

Influencerlar günümüzde toplumu yönlendirme konusunda büyük önem taşımaktadır. $\mathrm{Bu}$ influencerların yarattıkları sosyolojik (trendler), psikolojik (kendini görme), siyasi (partiye oy verme), ekonomik (ticari), pazarlama (marka) konularda etkiler araştırılmalıdır.

\section{Kaynakça}

Akın, M. Ş. (2019). Kullanıcının bağlamının önemi ve bağlamsal sorgulama. Istanbul Management Journal, 87, 1-25.

Aktaş, A., \& Şener, G. (2019). Nüfuz Pazarlamasında (Influencer Marketing) Mesaj Stratejileri. Erciyes İletişim Dergisi, 6(1), 399-422.

Aslan, A., \& Ünlü, D. G. (2016). Instagram Fenomenleri ve Reklam İlişkisi: Instagram Fenomenlerinin Gözünden Bir Değerlendirme. Maltepe Üniversitesi İletişim Fakültesi Dergisi, 3(2), 41-65.

Aydın Aslaner, D., \& Aydın, G. (2021). Dijitali Yeniden Okumak: Sosyal Etki Pazarlamsı ve Influencerler. Pamukkale University Journal of Social Sciences Institute, 30-41.

Bayuk, M. N., \& Aslan, M. (2018). Influencer Marketing (Hatırlı Pazarlama). Asos JournaL, 173-184.

Beckman, S. L., \& Barry, C. M. (2007). Innovation as a Learning Process: Embedding Design Thinking. California Management Review, 50(1), 25-49.

Brown, T. (2008). Design Thinking. Harvard Business Review, 5(3), 56-65.

Brown, T. (2009). Change by Design: How Design Thinking Transforms Organizations and Inspires Innovation. New York: Harper Business.

Canöz, K., Gülmez, Ö., \& Eroğlu, G. (2020). Pazarlamanın Yükselen Yıldızı Influencer Marketing: Influencer Takipçilerinin Satın Alma Davranışını Belirlemeye Yönelik Bir Araştırma. Selçuk Üniversitesi Sosyal Bilimler Meslek Yüksekokulu Dergisi, 23(1), 73 - 91.

Çaycı, B. (2019). Dijital İletişim Çağında Toplumun Medyatikleşmesiyle Dönüşen Şöhret Kültürü. İstanbul: İstanbul Ticaret Üniversitesi.

Eyel, C. Ş., \& Şen, B. (2020). Influencer Pazarlama ve Tüketicilerin Influencer'lere Yönelik Tutumlarının Satın Alma Niyeti Üzerindeki Etkisi. Atlas Sosyal Bilimler Dergisi, 1(5), 7-29.

Faulkner, L. (2003). Beyond the five-user assumption: Benefits of increased sample sizes in usability testing. Behavior Research Methods, Instruments, \& Computers, 35, 379-383.

Fettahlığlu, H. S., \& Çinkay, B. (2017). Sosyal Medyada Ünlü Kişi Kullanımının Tüketici Algısı Ve Satın Alma Niyeti İle İliş̧kisi: Kahramanmaraş İlinde Bir Uygulama. Social Sciences Studies Journal(4), 27-43.

Genç, Y., \& Kayalar, M. (2017). Üniversite Öğrencilerinin Sosyal Medya Kullanım Alışkanlıkları ve Satın Alma Davranışları Arasındaki İlişki. Asos Journal, 638-656. 
Gönülșen, G. (2020). Olumlu Marka İmajı Yaratmada Influencer Pazarlama Stratejisinin Marka Algısı Üzerindeki Etkisi: Foreo Türkiye Markasının Uygulamalarına Yönelik Bir Araştırma. Akdeniz Üniversitesi Sosyal Bilimler Enstitüsü Dergisi, 8, 9-34.

İşlek, M. S. (2012). Sosyal Medyanın Tüketici Davranışlarına Etkileri: Türkiye'deki Sosyal Medya Kullanıcıları Üzerine Bir Araştırma. Karaman: Yüksek Lisans Tezi.

Karabakan, F. (2020). Bir Pazarlama Aracı Olarak Sosyal Medya; Spor Markalarının Sosyal Medya Pazarlamalarının Üniversite Öğrencileri Satın Alma Davranışları Üzerine Etkisi. Asos Journal, 402-418.

Karadeniz, İ. (2019). Sosyal Medya Kullanıcılarının Seyahat Influencer Reklamlarına Yönelik Algılarının Tutum ve Destinasyon Seçimine Etkisi. Edirne: Trakya Üniversitesi,Sosyal Bilimler Enstitüsü.

Kılınç, M. (2020). Araştırma Şirketlerinin Sosyal Medya Kullanımı. İstanbul Aydın Üniversitesi Dergisi, 12(1), 9-20.

Kır, J., \& Öztürk, G. (2020). Türkiye'de İnfluencer Çalışmalarının Tüketicinin Satın Alma DavranışınaEtkisi. Uluslararası Halkla İlişkiler ve Reklam Çalışmaları Dergisi, 3(1), 44-66.

Korotina, A., \& Jargalsaikhan, T. (2016). Attitude towards Instagram micro-celebrities and their influence on consumers' purchasing decisions. Master's Thesis. Jönköping University.

Köse, G., \& Çakır, S. Y. (2019). Markaların Dijital Pazarlama ÇağındaTüketicileri Etkileşime İkna Etme Yolları:Influencer Pazarlama ve İçerik Pazarlamasına İlişkin Kavramsal Bir Çalışma. Kocaeli Üniversitesi Sosyal Bilimler Dergisi, 2(38), 205-222.

Mert, Y. L. (2018). Dijital Pazarlama Ekseninde Influencer Marketing Uygulamaları. Gümüşhane Üniversitesi İletişim Fakültesi Elektronik Dergisi, 6(2).

Özgen, E. (2012). Sosyal Medya ve Halkla İlişkilerde Değişen Medya Anlayışı, Sosyal Medya/Akademi. (E. Ö. Tolga Kara, Çev.) İstanbul: Beta Basım.

Pugazhenti, A. Ravindran, D.S. (2013). A Study on Impact of Celebrity Endorsements on Consumer Purchase Intention in Coimbatore City, India. Trends and Challenges in Global Business Management.

Rachbini, W. (2018). The Influence of Celebrity Endorsements on Purchase Intention (A Study on VIVO V7). IOSR Journal of Business and Management, 20(8), 59-66.

Sheldon, P. (2008). The Relationship Between Unwillingness-to-Communicate and Students Facebook Use. Journal of Media Psychology, 20(2), 67-75.

Szczurski, M. (2017). Social Media İnfluencer- A Lifestyle Or A Profession Of The Xxıst Century? International Journal of Management and Applied Science, 3(10), 4-7.

Tokay, S. B., \& Akın, M. Ş. (2020). Influencer takip algısına yönelik kullanıcı deneyimleri: Gelişim, amaç, gerçeklik. Elektronik Cumhuriyet İletişim Dergisi.

Ulaş, S., \& Alkan, Z. (2020). Marka Etkileşimi Ve Influencerlar (Etkileyiciler): Bobby Brown. Ege Üniversitesi İletişim Fakültesi Medya ve İletişim Araştırmaları Hakemli E-Dergisi(6), 91-115.

Ünal, A. Y. (2020, 10 02). Sosyal Medya Yasasııyla Türkiye»nin Verisi Türkiye»de Kalacak . 
Xiao, M., Wang, R., \& Chan-Olmsted, S. (2018). Factors Affecting YouTube Influencermarketing Credibility: a Heuristic-systematic Model. Journal of Media Business Studies, 1-26.

Yanar, K., \& Yılmaz, K. G. (2017). Sosyal Medyanın Satın Alma Öncesi ve Sonrası Tüketici Davranışına Etkisi Üzerine Bir Araștırma. Yönetim, Ekonomi ve Pazarlama Araştırmaları Dergisi, 1(2), 24-40.

Young, I. (2015). Practical Empathy: For Collaboration and Ceativity in Your Work. New York: Rosenfeld Media.

Zaltman, G. (2003). How Customers Think: Essential Insights into the Mind of the Markets. Boston: Harvard Business School Press.

Zaltman, G., \& MacCaba, D. (2007). Metaphor in Advertising. The SAGE Handbook of Advertising. The Sage Handbook of Advertising, 45, 135-154.

Zaltman, G., \& Zaltman, L. (2006). What Do What Do "Really Good" Managers and "Really Good" Researchers Want of One Another? The Handbook of Marketing Research: Uses, Misuses, and Future Advances, 37(2), 33-48.

Zaltman, G., \& Zaltman, L. (2008). Marketing Metaphoria: What Deep Metaphors Reveal about the Minds of Consumers. Boston: Harvard Business School Press.

Zietek, N. (2016). Influencer Marketing - The Characteristics and Components of Fashion. İsveç: The Swedish School of Textiles, University of Boras. 


\title{
User Experiences Regarding the Decision to Follow and Leave Influencer
}

\author{
Seher Büşra Tokay (MA Student) \\ Mustafa Şeref Akın (Prof. Dr.)
}

\section{Extended Abstract}

This article aims to investigate the reasons why followers decide to follow or quit influencers. Influencers try to achieve two goals at once: To increase the impact it creates on users and the number of followers. In this context, the study examined is an in-depth investigation of the followers who quit and continue following the influencers. As a result, there is an opportunity to learn the expectations, quitting, and follow-up behaviors of the followers who form the silent side in communication. The article evaluates the positive and negative feelings influencers make their followers feel. Interviews were held on the influencer that social media users follow, including their emotional and social experiences.

With the semi-structured interview technique, a qualitative research method, interviews were held on the influencer that social media users followed and unfollowed, including their emotional and social experiences.

Interview technique was used, and interviews were held on the social media users who followed or unfollowed the influencers about reasons behind following/unfollowing choices. In-depth interviews were conducted with 16 social media users who followed and unfollowed people, and their user experience is investigated. Positive emotions are asked in terms of personal development, direction, transparency, while negative emotions are asked in terms of deprivation, unfair business activity, fake showy life. Today, with the development of the digital world, social media phenomena, bloggers, YouTubers, and influencers have emerged. It has brought millions of people together with social media platforms and laid the groundwork for the sharing of different opinions, information, and experiences. The purpose of following influencers is to gain information. Here it is distinctive which information is presented for what purpose and how. Followers react when it presents unnecessary information for sale and with selffocus. It should be emphasized that digital marketing methods are of great importance for brands. The profits of the brand increases with the help of the influencers, who are the favorites of the brand's marketing field, reach the target audience and direct them to the purchasing tendency.

The influencer should inform the information like a personalized news channel. The information should be an eye-opener in an area in which that the follower is interested. Participants in the interviews follow influencers in the fields of food/gourmet, health, technology, psychology, entertainment, travel, medicine, and fashion. When the influencers go off-topic, their followers react. Motivation is the factor of the followers' in intensely following the influencer once the interests intersect. It ensures that the follower has the proper behavior by eliminating the lack of influencer information on a subject she or he has difficulty in achieving. Motivating the follower on a subject that he or she wants to achieve strengthens the bond.

Product promotion should be selective and motivational in the field of interest. When the influencer acts as a seller and prioritizes the brand, followers sense that behavior. First of 
all, influencers should choose the product by questioning what is good for the followers. They should not promote the product that they do not stand behind and are not part of their own experience. When the product is placed in the natural context of the influencer, the followers do not understand that they are in a marketing setup.

The influencer should show the information and product transparently. Although the influencer does it for commercial purposes, he or she should do so without overshadowing the sincere relationship and honesty. Manicure lives at first attract attention, but after a while followers move away from fake lives. Always laughing people, never-ending fun, always stylish clothes make followers question. When the lifestyles reflected by influencers are built on encouragement and falsehood, they drive the users away from themselves; on the contrary, they increase the number of followers due to being transparent and guiding when marketing products.

All these are interconnected as the link of a chain. While showing the fake lifestyle makes people feel deprived, marketing poor quality products due to commercial activity keeps the user away from the influencer. The fact that they do not communicate the deficiencies of inferior quality products causes the followers to stop following because they do not exhibit a transparent attitude. Reflecting the fake lifestyle, the influencer causes users to feel the boredom of fictional lives.

Especially after the influencer is successful (high number of followers and intense communication with its followers), it is experienced that she or he prioritizes herself/ himself instead of intersection issues and sincerity. Every photo now shows the influencer with his or her inflated ego. However, showing his/her followers that making mistakes is a part of learning and living in peace with himself has a positive effect. In one of the interviews, the participant describes the transition in the influencer that he or she followed. The transition of an influencer from the positive end to the negative end in the analysis framework shown by this article is indicated in Table 4. One of the participants points out that the influencer abandoned natural image in his mind, from the intersectional areas of food, fashion, and decoction. Now, the influencer he followed talks about professional make-up, getting personal clothes done, constantly photographing herself, playing on photos, and turning into a fashion icon. Authentic is in the flow from being natural to making a false life to the image. In fact, the participant says that he or she have thought they could be friends if he or she saw her on the road.

Keywords: Communication, Influencer, Motivating, Hegemonist. 
Bu makale intihal tespit yazılımlarıyla taranmıştır. Intihal tespit edilmemiş̧ir.

This article has been scanned by plagiarism detection softwares. No plagiarism detected.

Bu çalışmada "Yükseköğretim Kurumları Bilimsel Araştırma ve Yayın Etiği Yönergesi" kapsamında uyulması belirtilen kurallara uyulmuştur.

In this study, the rules stated in the "Higher Education Institutions Scientific Research and Publication Ethics Directive" were followed.

Yazarların çalışmadaki katkı oranları eşittir.

The authors' contribution rates in the study are equal.

Çalışma kapsamında herhangi bir kurum veya kişi ile çıkar çatışması bulunmamaktadır.

There is no conflict of interest with any institution or person within the scope of the study.

\section{Etik Kurul İzni I Ethics Committee Permission}

Erzincan Binali Yıldırım Üniversitesi İnsan Araştırmaları Etik Kurulu’nun 27.01.2021 tarih ve 02-04/ 02-08 sayılı kararları çerçevesinde çalışma etik açıdan bir sakınca içermemektedir.

Within the framework of the decisions taken by Erzincan Binali Yıldırım University Human Research Ethics Committee dated 27.01.2021 and numbered 02-04/02-08; the study does not contain any ethical issues. 